\title{
Repair and structural performance of initially cracked reinforced concrete Slabs
}

\begin{abstract}
Crack is one of the most common defects observed in reinforced concrete slabs and beams. Major cracks in concrete structures may occur due to overloading, corrosion of reinforcement or differential settlement of support. To restore the structural capacity of the distressed elements, retrofitting and/or strengthening are needed. There are different techniques available for retrofitting and strengthening of different reinforced concrete structural elements reported in the literature. This paper investigates the structural behaviour of cracked reinforced concrete one-way slab, which is repaired using different techniques. Five different techniques are used for the purpose of repair in the cracked concrete slab namely; cement grout, epoxy injection, ferrocement layer, carbon fibre strip and section enlargement. The slabs were loaded to failure stage and the structural response of each slab specimens have been predicted in terms of deflection, variation of strain in concrete and steel, collapse loads and the failure modes. The efficiency of different repair and strengthening techniques and their effects on the structural behaviour of cracked one-way reinforced concrete slab had been analyzed. It was observed that the type of repair technique used will affect the load carrying capacity of the slab and will lead to a redistribution of the strains and hence stresses in both concrete and steel reinforcement. All repair techniques are found to be able to restore or enhance the structural capacity of cracked concrete slabs.
\end{abstract}

Keyword: Repair and strengthening, Distressed concrete slab, Ferrocement, CFRP, Epoxy injection, Grouting, Section enlargement 